4 Jiankang Liu ${ }^{1,2} \cdot$ Yujing Jiang ${ }^{2, *} \cdot$ Sodai Ishizu ${ }^{2} \cdot$ Osamu Sakaguchi $^{3}$ 5

6

14 Corresponding author: Yujing Jiang

15 Email: jiang@nagasaki-u.ac.jp

Corresponding Address:

17 Graduate School of Engineering, Nagasaki University,1-14 Bunkyo-machi,

Phone: +81-95-819-2612 Fax: +81-95-819-2627

\section{Estimation of tunnel support pattern selection using artificial neural network}

1 College of Energy and Mining Engineering, Shandong University of Science and

Technology, Qingdao 266590, China

2 Graduate School of Engineering, Nagasaki University, Nagasaki 852-8521, Japan

3 Department of Civil Engineering, Konoike Construction Co., Ltd., Osaka 541-0057, Japan

8 852-8521 Nagasaki, Japan. 
3 Abstract: Effective selection of tunnel support patterns is one of the key factors affecting the

\section{Estimation of tunnel support pattern selection}

\section{using artificial neural network}

safety and operation cost of tunnel engineering. This study developed an artificial neural network (ANN) model for estimating tunnel support patterns ahead of tunnel face. In this respect, measure while drilling (MWD) data sets and tunnel support patterns during construction are introduced to the ANN models. The nonlinear relationship between the MWD data and the support patterns is estimated. The MWD data includes penetration rate $(\mathrm{PR})$, hammer pressure $(\mathrm{HP})$, rotation pressure $(\mathrm{RP})$, feed pressure $(\mathrm{FP})$, hammer frequency (HF) and specific energy (SE), which were collected from 97 drill holes of a high-speed railway tunnel project that is 3.88 kilometers long in Japan. A multi-layer perceptron analysis method is used based on different input sample sizes and different ANN structures. The results show that a strong correlation exists between MWD data and support patterns. It is traced that a neural network with six inputs (PR, HP, RP, FP, HF and SE) and one hidden layer is sufficient for the estimation of the support patterns. The increase in input sample size and hidden layer node has a positive optimizing effect on the performance of the ANN. However, an input sample size more than 6000 samples and a hidden layer larger than 30 nodes do not have a significant effect on optimizing the performance of the ANN. The size of input samples of 6000 and a three-layer neural network with topology 6-30-6 were found to be optimum. The proposed ANN model is suitable for selecting support patterns in practical engineering.

Keywords: Tunnel support pattern - Measure while drilling data - Artificial neural network $\cdot$ Network structure 


\section{Introduction}

The selection of tunnel support patterns heavily relies on the detailed detection of engineering rock mass characteristics (Bathke 1997; El-Naqa 2001; Marinos et al. 2006; Kaya et al. 2011; Morelli 2015; Cheng et al. 2019). In the past, the preliminary design of the support patterns was mainly based on empirical calculations and standardized rock mass classification systems. Due to the uncertainties in the rock mass behavior, the final selection of the support patterns was determined in construction process according to the exposed geological characteristics. The instability of such support patterns often occurs because of the sudden change of geological conditions ahead of the tunnel face (Kontogianni et al. 2004; Li et al. 2012; Wang et al. 2019). With the advancement of advanced detection technologies, it is possible to use advanced measure while drilling (MWD) technology for geological evaluation ahead of tunnel face (as shown in Fig. 1) (Schunnesson 1996; Sugawara et al. 2003; Høien and Nilsen 2014; Galende-Hernández et al. 2018). At the same time, applications of artificial neural networks (ANN) in decision-making and estimation of engineering problems have been attracted substantial interest to various computation sciences and engineering disciplines, since neural networks have the strong non-linear analysis capabilities and can provide engineers with scientific methods for optimal decision-making (Cai et al. 1998; Caglar and Arman 2007; Sarkar et al. 2010; Adoko et al. 2013; Gordan et al. 2016; Ozer et al. 2019).

In tunnel construction, although the site survey including rough estimation of rock mass structural properties is generally carried out, unexpected anomalies (i.e., cavities or water bearing, fractured, or relatively stronger zones) that may influence construction safety often exist (Otto et al. 2002; Ryu et al. 2011; Park et al. 2017; Han et al. 2020; Liu et al. 2018; Ren et al. 2019). Such anomalies can be detected by MWD system (Schunnesson 1997), which records the data information of operational parameters involved in drilling. For rotary drilling, Teale (1965) defined the concept of specific energy (SE) as the energy required to excavate unit volume of rock. Rabia (1985) compared different bit selections based on both cost per foot and SE and presented a simplified approach to bit selection that uses the principle of SE. Zhou et al. (2011) proposed an adaptive unsupervised approach based on MWD data to estimate the rock types and demonstrated that the proposed approach has a satisfactory 
1 performance in identification of rock types by experiments on actual data. Leung and 2 Scheding (2015) proposed a novel measure called modulated specific energy (SEM) for characterizing drilled material in open-pit coal mining, which can overcome the problems of low specificity and high variability observed in existing MWD approaches. Khorzoughi et al. (2018) correlated drill performance variables (MWD data) with measured fracture logs and identified that drill performance variables can accurately determine open versus closed fractures. In relation to studies developed for percussive and rotary-percussive drilling, Aoki et al. (1999) reported that a drill logging system had been developed in 1995 to evaluate the ground conditions at various depths by the data obtained while boring through the rock with a hydraulic drill. Yue et al. (2004) presented a methodology for identifying zones of volcanic weathering and decomposition grades in the ground through the MWD data monitored from rotary-percussive drilling. Factual data showed that the penetration rate parameter had a close correlation with decomposition grades in the ground. Peng et al. (2005) and Tang (2006) investigated the characteristics of void/fracture and the rock mass properties in roof rocks. The clear correlation between such geological properties and drilling parameters was confirmed. They found that the feed pressure can be used to detect the anomalies or discontinuities in the rock and to estimate the rock mass strength. Laudanski et al. (2012) evaluated the drilling measurements individually as well as combined into compound parameters to further enhance the ability of MWD to identify strata characteristics. It demonstrated that MWD can clearly provide qualitative evaluation of soil types, density and permeability using both rotary and percussion drilling methods. Ghosh et al. (2015) used MWD data to evaluate data trends among logged parameters and calculated average SE. They found that the estimation of SE through penetration rate and feed force was affected greatly by the hole length. From the correlation of MWD data with rock mass geo-mechanical features, Ghosh et al. (2017) suggested a method for distinguishing solid rock, fracture zones, cavities and damaged rock, based on the responses from the drill monitoring system. Navarro et al. (2018) investigated the mutual relation between MWD parameters. They determined that the feed pressure is a lead parameter that drives the adjustment of other parameters. The MWD method is usually implemented to quantify and visualize the geological conditions ahead of the tunnel face, yet directly estimating the support pattern selection is absent because 
1 of the difficulty of carrying out the MWD detection during the whole length of tunnel 2 construction.

3 Furthermore, in the last few years, artificial neural network (ANN) has been proved to be a powerful tool to settle geotechnical engineering problems (Alimoradi et al. 2008; Yilmaz 2009; Ocak and Seker 2012; Dantas Neto et al. 2017; Elkatatny 2019). Kanamoto et al. (2005) and Kimura et al. (2005) accurately estimated the different rock mass rating of a part of one tunnel using ANN based on partial MWD parameters. Guan et al. (2009) proposed a rheological parameter estimation technique using error backpropagation neural network (BPNN) and genetic algorithm, which was proved that the proposed technique can provide an optimal estimation of the rheological parameters and estimate the long-term deformations of mountain tunnels in the future. Mahdevari and Torabi (2012) developed a method based on ANN for estimation of convergence in tunnels and carried out a correlation analysis of the convergence data sets with geo-mechanical and geological parameters. They determined that cohesion, internal friction angle, Young's modulus and uniaxial compressive strength are the most effective factors and uniaxial tensile strength is the least effective one. Avunduk et al. (2014) suggested a model for estimation of the roadheaders based on ANN and concluded that the estimation capacity of ANN is better than the empirical models developed previously. Hasanipanah et al. (2016) proposed a new hybrid model of ANN optimized by particle swarm for estimating the maximum surface settlement caused by tunneling. Ghorbani and Firouzi Niavol (2017) applied ANN and evolutionary polynomial regressions to propose a method which can accurately reflect both static and coupled static-dynamic settlements. Ghorbani et al. (2018) used two different classes of ANNs to estimate the estimation of the support pressure of circular tunnels in elasto-plastic, strain-softening rock mass. There were many studies focused on geological and geo-mechanical interpretation of rock mass using MWD data and on solution of geotechnical engineering problems by using ANN. However, the studies involving the estimation of support patterns ahead of tunnel face based on MWD data using ANN, especially for the different support pattern selection under the same rock mass rating, have seldom been reported.

This paper aims at proposing an ANN model, based on the MWD data, to estimate the support pattern selection according to the rock mass condition ahead of the tunnel face. A total 
1 of 318, 649 MWD data sets along the whole length of a tunnel ware used for this assignment

2 by BPNN algorithm. Also, the feasibility of using ANN to estimate the support pattern selection was investigated. The effects of different input sample sizes and different neural network structures on the estimation performance of the ANN for tunnel support patterns were analyzed. Finally, the ANN model with optimal estimation performance was recommended.

\section{Case description}

The data sets used in the study were obtained from the new Nagasaki (east) tunnel project in Japan. The new Nagasaki (east) tunnel is located within the Nagasaki City in the southern part of Japan with an East-Westward trend as shown in Fig. 2. The tunnel is in the form of Single-Arch with a length of 3.88 kilometers. The approximate project cost is 60 million USD. The project started in 2013 and has finished in 2017. The tunnel was excavated using the new austrian tunnelling method. In this tunnel construction, many support patterns were applied, namely I-2-A(RC)(B), I-2-A(B), I-2-A(C), I-2-A(D), I-2-B(B), I-2-B (B) C, I-2- B(B) D [I-2-B (B) E], I-2- B (B) F, II-A-B(B) and II-B(B). It should be noted that due to the lack of part of the drilling data [corresponding to the tunnel with support patterns I-2-A(RC)(B), I-2-A(C), I-2-A(D) and I-2-B(B)F, totaling about 190 meters] collected from the construction site, the selection of the remaining six tunnel support patterns was predicted and analyzed in this study. A general view of the tunnel support patterns used in the on-site construction is shown in Fig. 3. Six support patterns were analyzed in this study. The class number of support patterns is shown in Table 1. The details of the six support patterns are exhibited in Fig. 4 and Table 2.

The hydraulic rotary-percussive drill as shown in Fig. 5a was used for drilling investigation ahead of tunnel face. The MWD data as shown in Fig. 6 obtained from the data collection device as shown in Fig. 5b include penetration rate (PR), hammer pressure (HP), rotation pressure (RP), feed pressure (FP), hammer frequency (HF) and SE. Each set of these data and the class number of the corresponding support pattern constitute a data set. All MWD data are output from the data recording apparatus in real time approximately every 0.25 seconds. The 
total number of all data sets from 97 drill holes is 318,649 .

In the first stage of the study, an ANN for estimating the class of support patterns was constructed using the numerous data sets. The parameters PR, HP, RP, FP, HF and SE were used as input parameters and the class number was used as output parameter. The range and distribution of the MWD data are tabulated in Table 3, in which the data are quite widely distributed.

\section{Model development}

ANN is a simplified mathematical model inspired by the biological structure and functioning of the brain. French and Recknagel (1970) and Park et al. (1991) defined an ANN as a structure consisting of closely connected adaptive processing elements that can perform large-scale parallel computing for data processing. The purpose of ANN studies is to adapt biological neural networks for data processing. Multi-layer perception is a development of the ANN. A typical network topology consists of the input layer, one or more hidden layers and the output layer. The ANN model has a high performance in the modeling of nonlinear multivariable problems, so which is also a powerful tool in geological engineering applications.

The input from the previous layer $\left(x_{i}\right)$ of each processing unit (PE) is multiplied by an adjustable connection weight $\left(w_{i j}\right)$ and summed at each PE and then a threshold $\left(\theta_{j}\right)$ is added. This summation result is then used as the input $\left(H_{j}\right)$ of the nonlinear transfer function, $f$, through which the output $y_{i}$ of the PE is generated. The output of each PE is used as the input of each PE of the next layer. This process is summarized in Eqs. 1 and 2 (Zurada 1992).

$$
\begin{gathered}
H_{j}=\sum_{i}^{n} w_{i j} x_{i}+\theta_{j} \\
y_{j}=f\left(H_{i}\right)
\end{gathered}
$$

The transfer function, also called the activation function, is designed to map a neuron, or layer, net output to its actual output. The class selection of these transfer functions, including simple linear or nonlinear step functions, depends on the purpose of the ANN. The most common transfer function implemented in the literature is the sigmoid function (Mitchell 
1 1997). The sigmoid function is preferred as the transfer function in this study. The generic

2 formula of the sigmoid function is given in Eq. 3.

$$
f(x)=\frac{1}{1+e^{-x}}
$$

There are many algorithms that can be applied to ANNs, however the BPNN algorithm is more general technology. It provides an effective learning method for multilayer perception neural networks (Law 2000). One of the purposes of this study is to calculate the best possible values of network weights. In this calculation, the BPNN algorithm is implemented by changing the weights and thresholds according to the results of the output layer. After seeing each input-output pair, the weights of the algorithm will be updated incrementally. The completion of one epoch means that all input-output pairs have been successfully seen and all corresponding weights have successfully adjusted. The process is then repeated for as many epochs as set. In this study, weight updating is an unsupervised iteration.

\section{The input and output layer sizes}

The input layer size is equal to the number of input layer nodes multiplied by the number of input samples corresponding to each node. Staufer and Fischer (1997) stated the input layer size is one of the important factors affecting the performance of neural networks. Garson (1998) suggested that input layer size should be 10-30 times the number of input nodes. However, in order to achieve near optimal performance, Hush (1989) recommended to use $[60 \times$ numbers of input nodes $\times$ (numbers of input nodes +1$)]$ training samples in the performance analysis of neural networks for classification problems while Swingler (1996) and Looney (1996) suggested using $20 \%$ and $25 \%$ of the data for testing, respectively. In the present study, in order to investigate the effect of the input layer size on the estimation performance of neural networks, 3000, 6000, 9000, 12000, 15000, 18000 and 21000 data sets (corresponding to 500,1000,1500, 2000, 2500, 3000 and 3500 data sets of each class of support patterns) were used in the training stage, and 600 data sets (corresponding to 100 data sets of the remainder of each class) were used in testing stage.

\section{Network structure}

Determining the number of hidden layers and the number of nodes in these layers is a major task in designing neural networks (Kavzoĝlu 2001). Garson (1998) and García-Pedrajas et al. 
1 (2005) reported that a single hidden layer is usually sufficient to solve most problems, especially classification issues. Kanellopoulos and Wilkinson (1997) stated that a second hidden layer is recommended when the output layer of the neural network has 20 (or more) nodes. Lippmann (1987) and Rumelhart et al. (1985) indicated that there is rarely an advantage in using more than one hidden layer. Therefore, one hidden layer was preferred in this study. However, the number of nodes in hidden layers is the most critical task in the BPNNs structure. The heuristics proposed for this purpose are summarized in Table 4. The number of nodes that may be used in the hidden layer varies between 6 and 18, depending on the proposed heuristics in the literature. However, in order to comprehensively analyze the influence of the number of hidden layer nodes on the classification performance of the neural networks, the number of hidden layer nodes was set as $6,8,10,12,14,16,18,20,30,40,50$, $60,70,80,90$ and 100 separately to conduct conducted trials.

\section{The learning rate and the momentum term}

The main disadvantage of the BPNN algorithm is the slow convergence rate, which is mainly related to the selected learning rate $(\eta)$. If the selected $\eta$ values is larger, the modification of the weight will be greater and the network convergence will be faster. However, the too large $\eta$ values will cause oscillations of updating process of weights. And, too small $\eta$ values will slow the convergence of the network and make the weight difficult to stabilize. The momentum term $(\alpha)$ has a stabilizing effect in the BPNN algorithm (Attoh-Okine 1999). It can be used to improve the convergence while reducing the oscillations of updating process of weights. Refenes et al. (1994) reported that for a layer and a two-layer network, $\eta=0.2$ and the momentum term of $0.3<\alpha \leq 0.5$ is the best combination of convergence. Wythoff (1993) set the momentum term between 0.4 and 0.9 . After several trials, $\eta$ values $=0.01$ and $\alpha=0.5$ were set to ensure the convergence of the algorithm before 500 iterations.

\section{Results and discussion}

In this study, different BPNN models were set up applying MATLAB software according to the combination of different numbers of training samples and different network structures defined above to search for the most effective ANN architecture. This study used MATLAB 
1 software to develop its own code, without using built-in ANN tool of the software. In these trials, $\eta$ of 0.01 and $\alpha$ of 0.5 were used. Testing and validation of the BPNN models were done with date sets shown above. These date sets were randomly selected from the total data sets. The results are presented to demonstrate the performance of the networks. Average accuracy ( $\bar{A}, \bar{A}=$ the correctly estimated number of output samples / total number of output samples) and average computing time $(\bar{T})$ were taken as the performance measures to assess the performance and stability of neural networks. And, average accuracy $(\bar{A}, \bar{A}=A / 10)$ and average computing time $(\bar{T})(\bar{T}=T / 10)$ were obtained from 10 trials under the same experimental conditions.

The results obtained for these models are listed in Appendix (A) and shown in Figs. 7 and 8. Figure 7 shows a graph with variations in $\bar{A} s$ with different numbers of training samples and hidden layer nodes. For all training samples, the $\bar{A} s$ of the estimated results of the BPNN models increase with the increase in the number of hidden layer nodes. The growth curves become horizontal, until the hidden layer node equals 30 . In addition, the $\bar{A} s$ are lowest as the number of samples is 3000 , and the difference is small when the number of samples is $6000,9000,12000,15000,18000$ and 21000 . For example, when the number of the hidden layer node equals 30 , the $\bar{A}$ s equal to $0.839,0.839,0.843,0.841,0.847$ and 0.844 respectively (as the number of training samples is 6000, 9000, 12000, 15000, 18000 and 21000, respectively).

Figure 8 illustrates variations in the $\bar{T}$ per node $(\bar{T}$ per node $=\bar{T} /$ the number of nodes in hidden layer) with different numbers of training samples and hidden layer nodes. For different training samples, when the number of nodes in hidden layer is more than 30 , the $\bar{T}$ per node value tend to fixed values of 4, 8, 11, 15, 20, 23 and 27 (as the number of training samples is $3000,6000,9000,12000,15000,18000$ and 21000, respectively). When the number of nodes in hidden layer is more than 30 , the $\bar{T}$ value can be calculated by the formula: $\bar{T}=\bar{T}_{f} \square N_{h}$ (where, $\bar{T}_{f}=$ the fixed value of the $\bar{T}$ per node, $N_{h}=$ the number of nodes in hidden layer), but the performance of the network does not improve. Thus, observing Figs. 7, 10, and Appendix (A) and considering the less $\bar{T}$ and the guaranteed performance, 
1 the optimal neural network model is proposed with the number of training samples of 6000 and the hidden layer nodes of 30 . The estimation results of six classes of the support patterns for the preferred BPNN model have relatively high $\bar{A} s$, as shown in Table 5.

Figure 9 illustrates variations in $\bar{A} s$ of estimation results for each class of support patterns in 10 trials based on the preferred BPNN model. The $\bar{A} s$ of estimation results of the six support patterns have a high robustness, especially for class 1 and class 2 . In addition, the comparison between the estimation results and the real classes of the second experiment is shown in Fig. 10. The $\bar{A}$ value of $0.884,0.866,0.819,0.742,0.805$ and 0.920 (corresponding to six classes of support patterns, respectively). Except for the $\bar{A}$ value of class 4 is less than 0.8 , the other classes obtain a higher $\bar{A}$ value. This result indicates that the MWD data can characterize the rock mass condition ahead of tunnel face and there is a high correlation between such measured data and support patterns.

\section{Conclusions}

This study presented an artificial neural network (ANN) model to estimate support pattern selection ahead of tunnel face based on measure while drilling (MWD) data. The MWD data was obtained from 97 drill holes of a high-speed railway tunnel project carried out along 3.88 kilometers long in Japan. In order to obtain the optimal neural network model, controlled trials are conducted considering different input sample sizes and hidden layer sizes. An ANN with 6 inputs (penetration rate (PR), hammer pressure (HP), rotation pressure (RP), feed pressure (FP), hammer frequency (HF) and specific energy (SE)) and 6 outputs (6 dimensions correspond to 6 classes of support patterns) is designed for estimating the selection of support patterns. The architecture of the error backpropagation neural network (BPNN) consists of 1 hidden layer. Numerous training trials are performed starting from a single node to 100 nodes in the hidden layer. Accuracy and computing time of each trial are recorded to obtain the performance index.

The results show that strong correlation exists between MWD data and support patterns, with the optimal estimation results of the average accuracy $(\bar{A})$ values corresponding to six 
1 classes of support patterns are, respectively, $0.884,0.866,0.819,0.742,0.805$ and 0.920 .

2 The selection of tunnel support patterns is mainly influenced by the geotechnical condition of

3 the rock mass. The estimation performance of ANN is affected by the input sample sizes and

4 the hidden layer sizes. An input sample size greater than 6000 samples and a hidden layer size

5 greater than 30 neurons do not have an optimizing effect on the performance. An optimal

6 ANN model is obtained with 6000 samples in input layer and 1 hidden layer with 30 nodes.

7 The ANN draws an excellent performance using only $2 \%$ of the total samples as training

8 samples and is a convenient tool for estimating tunnel support pattern selection ahead of tunnel face. It can be stated that the estimation of tunnel support pattern selection using ANN can be used as an essential knowledge of project engineers for improving the safety and reliability of tunnel engineering. correlation between the MWD data and the support pattern selection. As a prior work, the ANN models with other outstanding algorithms are not adopted but will be considered in the future studies. The present study established the BPNN models with all the MWD data parameters, which is therefore merely an initial step to explore the concerned topic. More combinatorial and complex parameters based on the MWD data parameters need to be considered to improve the estimation performance of the ANN. Besides, more verification and analysis based on other tunnel projects under similar geological conditions should be carried out to understand the adaptability of the proposed ANN estimation model in the future works. 


\section{Acknowledgments}

2 The authors gratefully acknowledge support of Civil Engineering Department, Technical

3 Division, Konoike Construction Japan for providing field data and sharing experience on

4 tunnel construction. In addition, this work was funded by China Scholarship Council (CSC $5 \quad$ No. 201708370104).

6 


\section{References}

Adoko AC, Jiao YY, Wu L, Wang H, Wang ZH (2013) Predicting tunnel convergence using multivariate adaptive regression spline and artificial neural network. Tunn Undergr Space Technol 38:368-376 https://doi.org/10.1016/j.tust.2013.07.023

Alimoradi A, Moradzadeh A, Naderi R, Salehi MZ, Etemadi A (2008) Prediction of geological hazardous zones in front of a tunnel face using TSP-203 and artificial neural networks. Tunn Undergr Space Technol 23:711-717 https://doi.org/10.1016/j.tust.2008.01.001

Aoki K, Shirasagi S, Yamamoto T, Inou M, Nishioka K (1999) Examination of the application of drill Logging to predict ahead of the tunnel face. In: Proceedings of the 54th Annual Conference of the Japan Society of Civil Engineers, Tokyo, Japan, September 1999. pp 412-413

Attoh-Okine NO (1999) Analysis of learning rate and momentum term in backpropagation neural network algorithm trained to predict pavement performance. Adv Eng Software 30:291-302 https://doi.org/10.1016/S0965-9978(98)00071-4

Avunduk E, Tumac D, Atalay AK (2014) Prediction of roadheader performance by artificial neural network. Tunn Undergr Space Technol 44:3-9 https://doi.org/10.1016/j.tust.2014.07.003

Bathke CG (1997) Systems analysis in support of the selection of the ARIES-RS design point. Fusion Eng Des 38:59-86 https://doi.org/10.1016/S0920-3796(97)00112-9

Caglar N, Arman H (2007) The applicability of neural networks in the determination of soil profiles. Bull Eng Geol Environ 66:295-301 10.1007/s10064-006-0075-9

Cai J, Zhao J, Hudson J (1998) Computerization of rock engineering systems using neural networks with an expert system. Rock Mech Rock Eng 31:135-152

Cheng Z, Yang S, Li L, Zhang L (2019) Support working resistance determined on top-coal caving face based on coal-rock combined body. Geomechanics Engineering 19:255-268 https://doi.org/10.12989/gae.2019.19.3.255

Dantas Neto SA, Indraratna B, Oliveira DAF, de Assis AP (2017) Modelling the shear 
behaviour of clean rock discontinuities using artificial neural networks. Rock Mech Rock Eng 50:1817-1831 http://10.1007/s00603-017-1197-z

El-Naqa A (2001) Application of RMR and Q geomechanical classification systems along the proposed Mujib Tunnel route, central Jordan. Bull Eng Geol Environ 60:257-269

Elkatatny S (2019) Development of a new rate of penetration model using self-adaptive differential evolution-artificial neural network. Arabian J Geosci 12:19 https://doi.org/10.1007/s12517-018-4185-z

French M, Recknagel F (1970) Modeling of algal blooms in freshwaters using artificial neural networks. WIT Trans Ecol Environ 6

Galende-Hernández M, Menéndez M, Fuente MJ, Sainz-Palmero GI (2018)

Monitor-While-Drilling-based estimation of rock mass rating with computational intelligence: The case of tunnel excavation front. Autom Constr 93:325-338 https://doi.org/10.1016/j.autcon.2018.05.019

Gao D (1998) On structures of supervised linear basis function feedforward three-layered neural networks. Chinese Journal of Computers 1

García-Pedrajas N, Hervás-Martínez C, Ortiz-Boyer D (2005) Cooperative Coevolution of Artificial Neural Network Ensembles for Pattern Classification. IEEE Trans Evol Comput 9:271-302

Garson GD (1998) Neural networks: An introductory guide for social scientists. Sage, London Ghorbani A, Firouzi Niavol M (2017) Evaluation of induced settlements of piled rafts in the coupled static-dynamic loads using neural networks and evolutionary polynomial regression. Applied Computational Intelligence and Soft Computing 2017

Ghorbani A, Hasanzadehshooiili H, Sadowski Ł (2018) Neural prediction of tunnels’ support pressure in elasto-plastic, strain-softening rock mass. Applied Sciences 8:841

Ghosh R, Danielsson M, Gustafson A, Falksund H, Schunnesson H (2017) Assessment of rock mass quality using drill monitoring technique for hydraulic ITH drills. Int J Min Miner Process Eng 8:169-186

Ghosh R, Schunnesson H, Kumar U (2015) The use of specific energy in rotary drilling: the effect of operational parameters. In: Proceedings of the 37th International Symposium, May 2015. Application of Computers and Operations Research in the Mineral Industry. 
pp 713-723

Gordan B, Jahed Armaghani D, Hajihassani M, Monjezi M (2016) Prediction of seismic slope stability through combination of particle swarm optimization and neural network. Eng Comput 32:85-97 Http://10.1007/s00366-015-0400-7

Guan Z, Jiang Y, Tanabashi Y (2009) Rheological parameter estimation for the prediction of long-term deformations in conventional tunnelling. Tunn Undergr Space Technol 24:250-259 https://doi.org/10.1016/j.tust.2008.08.001

Han W, Li G, Sun Z, Luan HJ, Liu CZ,Wu XL (2020) Numerical investigation of a foundation pit supported by a composite soil nailing structure. Symmetry 12(2):252

Hasanipanah M, Noorian-Bidgoli M, Jahed Armaghani D, Khamesi H (2016) Feasibility of PSO-ANN model for predicting surface settlement caused by tunneling. Eng Comput 32:705-715 Http://10.1007/s00366-016-0447-0

Hecht-Nielsen R Kolmogorov's mapping neural network existence theorem. In: Proceedings of the international conference on Neural Networks, 1987. IEEE Press New York, pp $11-14$

Høien AH, Nilsen B (2014) Rock mass grouting in the Løren Tunnel: case study with the main focus on the groutability and feasibility of drill parameter interpretation. Rock Mech Rock Eng 47:967-983 Http://10.1007/s00603-013-0386-7

Hush DR (1989) Classification with neural networks: a performance analysis. In: Proceedings of the IEEE International Conference on Systems Engineering, August 1989. pp 277-280

Kaastra I, Boyd M (1996) Designing a neural network for forecasting financial and economic time series. Neurocomputing 10:215-236 https://doi.org/10.1016/0925-2312(95)00039-9

Kanamoto T, Ohnishi Y, Nishiyama S, Uehara S, Kimura T, Yamashita M (2005) Study on application of neural network to evaluation of geological condition using drilling survey system. Paper presented at the Proceedings of the 60th JSCE Annual Meeting, 2005

Kanellopoulos I, Wilkinson GG (1997) Strategies and best practice for neural network image classification. Int J Remote Sens 18:711-725

Kavzoĝlu T (2001) An investigation of the design and use of feed-forward artificial neural networks in the classification of remotely sensed images. Dissertation, University of Nottingham 
1 Kaya A, Bulut F, Sayin A (2011) Analysis of support requirements for a tunnel portal in weak rock: A case study from Turkey. Scientific Research and Essays 6:6566-6583

Khorzoughi MB, Hall R, Apel D (2018) Rock fracture density characterization using measurement while drilling (MWD) techniques. International Journal of Mining Science and Technology 28:859-864 https://doi.org/10.1016/j.ijmst.2018.01.001

Kimura T, Ohnishi Y, Nishiyama S, Ishiyama K (2005) Study on prediction ahead of tunnel face by using drilling survey method. Geoinformatics 16:191

Kontogianni V, Tzortzis A, Stiros S (2004) Deformation and failure of the Tymfristos tunnel, Greece. J Geotech Geoenviron Eng 130:1004-1013

Laudanski G, Reiffsteck P, Tacita J, Desanneaux G, Benoît J (2012) Experimental study of drilling parameters using a test embankment. In: Proceedings of the Fourth International Conference on Geotechnical and Geophysical Site Characterization, Pernambuco,Brazil, September 2012. CRC Press Porto de Galinhas-Pernambuco, pp 435-440

Law R (2000) Back-propagation learning in improving the accuracy of neural network-based tourism demand forecasting. Tourism Management 21:331-340 https://doi.org/10.1016/S0261-5177(99)00067-9

Leung R, Scheding S (2015) Automated coal seam detection using a modulated specific energy measure in a monitor-while-drilling context. Int J Rock Mech Min Sci 75:196-209 https://doi.org/10.1016/j.ijrmms.2014.10.012

Li L et al. (2012) Spatial deformation mechanism and load release evolution law of surrounding rock during construction of super-large section tunnel with soft broken surrounding rock masses. Chin J Rock Mechan Eng 10:2109-2118

Lippmann RP (1987) Anintroduction to computing with neural nets. IEEE Assp magazine $4: 4-22$

Liu B, Chen L, Li S, Xu X, Liu L, Song J, Li M (2018) A new 3D observation system designed for a seismic ahead prospecting method in tunneling. Bull Eng Geol Environ 77:1547-1565 10.1007/s10064-017-1131-3

Looney CG (1996) Advances in feedforward neural networks: demystifying knowledge acquiring black boxes. IEEE Transactions on Knowledge \& Data Engineering:211-226 Mahdevari S, Torabi SR (2012) Prediction of tunnel convergence using artificial neural 
networks. Tunn Undergr Space Technol 28:218-228

https://doi.org/10.1016/j.tust.2011.11.002

Marinos P, Hoek E, Marinos V (2006) Variability of the engineering properties of rock masses quantified by the geological strength index: the case of ophiolites with special emphasis on tunnelling. Bull Eng Geol Environ 65:129-142 Http://10.1007/s10064-005-0018-x

Masters T (1993) Practical neural network recipes in C++. Morgan Kaufmann, San Francisco

Mitchell TM (1997) Evaluating hypotheses. Machine Learning:128-153

Morelli GL (2015) Variability of the GSI index estimated from different quantitative methods. Geotech Geol Eng 33:983-995 Http://10.1007/s10706-015-9880-x

Navarro J, Sanchidrian JA, Segarra P, Castedo R, Paredes C, Lopez LM (2018) On the mutual relations of drill monitoring variables and the drill control system in tunneling operations. Tunn Undergr Space Technol 72:294-304 https://doi.org/10.1016/j.tust.2017.10.011

Ocak I, Seker SE (2012) Estimation of elastic modulus of intact rocks by artificial neural network. Rock Mech Rock Eng 45:1047-1054 http://10.1007/s00603-012-0236-z

Otto R, Button E, Bretterebner H, Schwab P (2002) The application of TRT-true reflection tomography-at the Unterwald Tunnel. Felsbau 20:51-56

Ozer U, Karadogan A, Ozyurt MC, Sahinoglu UK, Sertabipoglu Z (2019) Environmentally sensitive blasting design based on risk analysis by using artificial neural networks. Arabian J Geosci 12:60 10.1007/s12517-018-4218-7

Paola J (1994) Neural network classification of multispectral imagery. Diaaertation, The University of Arizona

Park DC, El-Sharkawi M, Marks R, Atlas L, Damborg M (1991) Electric load forecasting using an artificial neural network. IEEE Trans Power Syst 6:442-449

Park J, Lee KH, Kim BK, Choi H, Lee IM (2017) Predicting anomalous zone ahead of tunnel face utilizing electrical resistivity: II. Field tests. Tunn Undergr Space Technol 68:1-10 https://doi.org/10.1016/j.tust.2017.05.017

Peng S, Tang D, Sasaoka T, Luo Y, Finfinger G, Wilson G (2005) A method for quantitative void/fracture detection and estimation of rock strength for underground mine roof. In: Proceedings of 24th International Conference on Ground Control in Mining, Morgantown, USA, August 2005. pp 195-197 
1 Rabia H (1985) Specific energy as a criterion for bit selection. Journal of petroleum technology 37:1,225-221,229

Refenes AN, Zapranis A, Francis G (1994) Stock performance modeling using neural networks: a comparative study with regression models. Neural networks 7:375-388

Ren F, Zhu C, He M (2019) Moment Tensor Analysis of Acoustic Emissions for Cracking Mechanisms During Schist Strain Burst. Rock Mechanics Rock Engineering:1-12 https://doi.org/10.1007/s00603-019-01897-3

Ripley BD (1993) Statistical aspects of neural networks. Networks and chaos—statistical and probabilistic aspects 50:40-123

Rumelhart DE, Hinton GE, Williams RJ (1985) Learning internal representations by error propagation. California Univ San Diego La Jolla Inst for Cognitive Science,

Ryu HH, Cho GC, Yang SD, SHIN HK (2011) Development of tunnel electrical resistivity prospecting system and its applicaton. Geoelectric Monitoring:179

Sarkar K, Tiwary A, Singh TN (2010) Estimation of strength parameters of rock using artificial neural networks. Bull Eng Geol Environ 69:599-606 $10.1007 / \mathrm{s} 10064-010-0301-3$

Schunnesson H (1996) RQD predictions based on drill performance parameters. Tunn Undergr Space Technol 11:345-351

Schunnesson H (1997) Drill process monitoring in percussive drilling for location of structural features, lithological boundaries and rock properties, and for drill productivity evaluation. Dissertation, Luleå tekniska universitet

Staufer P, Fischer MM (1997) Spectral pattern recognition by a two-layer perceptron: effects of training set size. In: Neurocomputation in Remote Sensing Data Analysis. Springer, Berlin, pp 105-116

Sugawara J, Yue Z, Tham L, Law K, Lee C (2003) Weathered rock characterization using drilling parameters. Canadian geotechnical journal 40:661-668

Swingler K (1996) Applying neural networks: a practical guide. Morgan Kaufmann, San Francisco

Tang X (2006) Development of real time roof geology detection system using drilling parameters during roof bolting operation. Dissertations, West Virginia University 
1 Teale R (1965) The concept of specific energy in rock drilling. In: International Journal of Rock Mechanics and Mining Sciences \& Geomechanics Abstracts, 1965. vol 1. Elsevier, pp 57-73

Wang J, Li S-c, Li L-p, Lin P, Xu Z-h, Gao C-1 (2019) Attribute recognition model for risk assessment of water inrush. Bull Eng Geol Environ 78:1057-1071 https://doi.org/10.1007/s10064-017-1159-4

Wythoff BJ (1993) Backpropagation neural networks: a tutorial. Chemometrics and Intelligent Laboratory Systems 18:115-155

Yilmaz I (2009) A case study from Koyulhisar (Sivas-Turkey) for landslide susceptibility mapping by artificial neural networks. Bull Eng Geol Environ 68:297-306 https://doi.org/10.1007/s10064-009-0185-2

Yue ZQ, Lee CF, Law KT, Tham LG (2004) Automatic monitoring of rotary-percussive drilling for ground characterization_-illustrated by a case example in Hong Kong. Int J Rock Mech Min Sci 41:573-612 https://doi.org/10.1016/j.ijrmms.2003.12.151

Zhou H, Hatherly P, Ramos F, Nettleton E An adaptive data driven model for characterizing rock properties from drilling data. In: 2011 IEEE International Conference on Robotics and Automation, Shanghai, China, May 2011. IEEE, pp 1909-1915

Zurada JM (1992) Introduction to artificial neural systems, West, St. Paul, Minn 
2 The results obtained for different models ( $N_{\mathrm{ts}}$ : Number of training samples $\bar{A}$ : average accuracies

$3 \quad \bar{T}$ : average computing times)

\begin{tabular}{|c|c|c|c|c|c|c|c|c|c|}
\hline No. & $N_{\mathrm{ts}}$ & $\begin{array}{l}\text { Network } \\
\text { structure }\end{array}$ & $\bar{A}$ & $\bar{T}$ & No. & $N_{\mathrm{ts}}$ & $\begin{array}{l}\text { Network } \\
\text { structure }\end{array}$ & $\bar{A}$ & $\bar{T}$ \\
\hline 1 & 3000 & 6-6-6 & 0.625 & 32.52 & 57 & 12000 & $6-30-6$ & 0.844 & 481.93 \\
\hline 2 & 3000 & $6-8-6$ & 0.726 & 39.60 & 58 & 12000 & $6-40-6$ & 0.843 & 627.40 \\
\hline 3 & 3000 & $6-10-6$ & 0.743 & 46.99 & 59 & 12000 & $6-50-6$ & 0.857 & 785.90 \\
\hline 4 & 3000 & $6-12-6$ & 0.777 & 53.73 & 60 & 12000 & $6-60-6$ & 0.864 & 902.55 \\
\hline 5 & 3000 & $6-14-6$ & 0.781 & 61.04 & 61 & 12000 & $6-70-6$ & 0.857 & 1044.66 \\
\hline 6 & 3000 & $6-16-6$ & 0.778 & 67.79 & 62 & 12000 & $6-80-6$ & 0.863 & 1185.99 \\
\hline 7 & 3000 & $6-18-6$ & 0.807 & 75.32 & 63 & 12000 & $6-90-6$ & 0.851 & 1329.98 \\
\hline 8 & 3000 & $6-20-6$ & 0.801 & 81.85 & 64 & 12000 & $6-100-6$ & 0.866 & 1482.69 \\
\hline 9 & 3000 & $6-30-6$ & 0.820 & 117.16 & 65 & 15000 & $6-6-6$ & 0.658 & 170.31 \\
\hline 10 & 3000 & $6-40-6$ & 0.836 & 156.77 & 66 & 15000 & $6-8-6$ & 0.700 & 207.90 \\
\hline 11 & 3000 & $6-50-6$ & 0.840 & 191.76 & 67 & 15000 & $6-10-6$ & 0.748 & 260.11 \\
\hline 12 & 3000 & $6-60-6$ & 0.834 & 226.58 & 68 & 15000 & $6-12-6$ & 0.784 & 290.86 \\
\hline 13 & 3000 & $6-70-6$ & 0.847 & 258.01 & 69 & 15000 & $6-14-6$ & 0.789 & 332.43 \\
\hline 14 & 3000 & $6-80-6$ & 0.840 & 288.74 & 70 & 15000 & $6-16-6$ & 0.814 & 370.22 \\
\hline 15 & 3000 & $6-90-6$ & 0.838 & 323.84 & 71 & 15000 & $6-18-6$ & 0.819 & 409.76 \\
\hline 16 & 3000 & $6-100-6$ & 0.850 & 358.32 & 72 & 15000 & $6-20-6$ & 0.835 & 452.75 \\
\hline 17 & 6000 & $6-6-6$ & 0.667 & 64.34 & 73 & 15000 & $6-30-6$ & 0.841 & 646.23 \\
\hline 18 & 6000 & $6-8-6$ & 0.713 & 77.29 & 74 & 15000 & $6-40-6$ & 0.848 & 832.62 \\
\hline 19 & 6000 & $6-10-6$ & 0.767 & 92.09 & 75 & 15000 & $6-50-6$ & 0.858 & 1025.32 \\
\hline 20 & 6000 & $6-12-6$ & 0.804 & 105.59 & 76 & 15000 & $6-60-6$ & 0.862 & 1217.78 \\
\hline 21 & 6000 & $6-14-6$ & 0.792 & 119.72 & 77 & 15000 & $6-70-6$ & 0.858 & 1393.02 \\
\hline 22 & 6000 & $6-16-6$ & 0.812 & 133.91 & 78 & 15000 & $6-80-6$ & 0.859 & 1594.97 \\
\hline 23 & 6000 & $6-18-6$ & 0.821 & 146.61 & 79 & 15000 & $6-90-6$ & 0.861 & 1785.53 \\
\hline 24 & 6000 & $6-20-6$ & 0.823 & 160.08 & 80 & 15000 & $6-100-6$ & 0.857 & 1982.60 \\
\hline 25 & 6000 & $6-30-6$ & 0.839 & 238.43 & 81 & 18000 & $6-6-6$ & 0.649 & 210.49 \\
\hline 26 & 6000 & $6-40-6$ & 0.847 & 310.50 & 82 & 18000 & $6-8-6$ & 0.728 & 257.58 \\
\hline 27 & 6000 & $6-50-6$ & 0.843 & 380.44 & 83 & 18000 & $6-10-6$ & 0.758 & 304.03 \\
\hline 28 & 6000 & $6-60-6$ & 0.848 & 451.46 & 84 & 18000 & $6-12-6$ & 0.791 & 351.97 \\
\hline 29 & 6000 & $6-70-6$ & 0.850 & 527.90 & 85 & 18000 & $6-14-6$ & 0.811 & 385.43 \\
\hline 30 & 6000 & $6-80-6$ & 0.854 & 594.81 & 86 & 18000 & $6-16-6$ & 0.817 & 410.93 \\
\hline 31 & 6000 & $6-90-6$ & 0.856 & 647.51 & 87 & 18000 & $6-18-6$ & 0.814 & 446.27 \\
\hline 32 & 6000 & $6-100-6$ & 0.853 & 715.04 & 88 & 18000 & $6-20-6$ & 0.827 & 488.55 \\
\hline 33 & 9000 & $6-6-6$ & 0.655 & 97.71 & 89 & 18000 & $6-30-6$ & 0.847 & 701.35 \\
\hline 34 & 9000 & $6-8-6$ & 0.724 & 125.41 & 90 & 18000 & $6-40-6$ & 0.852 & 912.10 \\
\hline 35 & 9000 & $6-10-6$ & 0.763 & 147.86 & 91 & 18000 & $6-50-6$ & 0.862 & 1121.67 \\
\hline 36 & 9000 & $6-12-6$ & 0.785 & 162.22 & 92 & 18000 & $6-60-6$ & 0.859 & 1346.63 \\
\hline 37 & 9000 & 6-14-6 & 0.789 & 186.46 & 93 & 18000 & $6-70-6$ & 0.860 & 1564.15 \\
\hline 38 & 9000 & $6-16-6$ & 0.807 & 213.57 & 94 & 18000 & $6-80-6$ & 0.856 & 1775.91 \\
\hline 39 & 9000 & $6-18-6$ & 0.798 & 226.23 & 95 & 18000 & $6-90-6$ & 0.861 & 1992.42 \\
\hline
\end{tabular}




\begin{tabular}{ccccc|ccccc}
\hline 40 & 9000 & $6-20-6$ & 0.814 & 248.16 & 96 & 18000 & $6-100-6$ & 0.863 & 2202.52 \\
41 & 9000 & $6-30-6$ & 0.839 & 354.97 & 97 & 21000 & $6-6-6$ & 0.641 & 264.03 \\
42 & 9000 & $6-40-6$ & 0.845 & 466.27 & 98 & 21000 & $6-8-6$ & 0.712 & 269.94 \\
43 & 9000 & $6-50-6$ & 0.849 & 570.81 & 99 & 21000 & $6-10-6$ & 0.769 & 317.92 \\
44 & 9000 & $6-60-6$ & 0.850 & 681.77 & 100 & 21000 & $6-12-6$ & 0.779 & 384.37 \\
45 & 9000 & $6-70-6$ & 0.854 & 795.41 & 101 & 21000 & $6-14-6$ & 0.798 & 421.30 \\
46 & 9000 & $6-80-6$ & 0.847 & 879.06 & 102 & 21000 & $6-16-6$ & 0.807 & 466.45 \\
47 & 9000 & $6-90-6$ & 0.860 & 984.95 & 103 & 21000 & $6-18-6$ & 0.829 & 536.72 \\
48 & 9000 & $6-100-6$ & 0.853 & 1089.28 & 104 & 21000 & $6-20-6$ & 0.830 & 585.45 \\
49 & 12000 & $6-6-6$ & 0.673 & 137.86 & 105 & 21000 & $6-30-6$ & 0.844 & 845.34 \\
50 & 12000 & $6-8-6$ & 0.707 & 166.43 & 106 & 21000 & $6-40-6$ & 0.865 & 1064.07 \\
51 & 12000 & $6-10-6$ & 0.766 & 189.64 & 107 & 21000 & $6-50-6$ & 0.853 & 1374.39 \\
52 & 12000 & $6-12-6$ & 0.792 & 221.92 & 108 & 21000 & $6-60-6$ & 0.863 & 1631.82 \\
53 & 12000 & $6-14-6$ & 0.800 & 251.86 & 109 & 21000 & $6-70-6$ & 0.856 & 1890.87 \\
54 & 12000 & $6-16-6$ & 0.799 & 277.25 & 110 & 21000 & $6-80-6$ & 0.860 & 2144.15 \\
55 & 12000 & $6-18-6$ & 0.815 & 305.10 & 111 & 21000 & $6-90-6$ & 0.863 & 2401.31 \\
56 & 12000 & $6-20-6$ & 0.830 & 339.63 & 112 & 21000 & $6-100-6$ & 0.870 & 2655.73 \\
\hline
\end{tabular}


1 Table Captions

2 Table 1 The classification number of support patterns

3 Table 2 The comparison of details of the six support patterns

$4 \quad$ Table 3 Basic descriptive statistics for the original MWD data

5 Table 4 The proposed number of nodes in hidden layer $\left(N_{\mathrm{i}}\right.$ : number of input nodes, $N_{0}$ :

6 number of output nodes)

7 Table 5 The average accuracies of estimation of the support patterns (with the number of

8 nodes in hidden layer $=30$, the number of training samples $=6000$ )

10 Figure Captions

11 Fig. 1 Diagram of direct drilling method

12 Fig. 2 Location of new Nagasaki (east) tunnel, Nagasaki, Japan

13 Fig. 3 General view of the tunnel support patterns

$14 \quad$ Fig. 4 The details of the six support patterns

15 Fig. 5 The drill and data collection device:(a) the hydraulic rotary percussion drill, (b) the measure while drilling (MWD) device

17 Fig. 6 Visualization of MWD data recorded

Fig. 7 Variations of the average accuracies with different number of training samples and nodes in hidden layer

Fig. 8 Variations of the average computing time per node

Fig. 9 Variations of the accuracies of estimation with each support pattern in 10 trials

Fig. 10 Estimated results for the test sample 


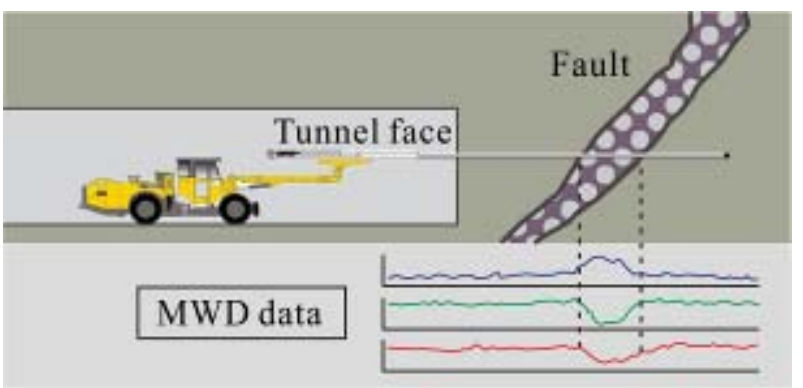

Fig.1 Diagram of direct drilling method

26 


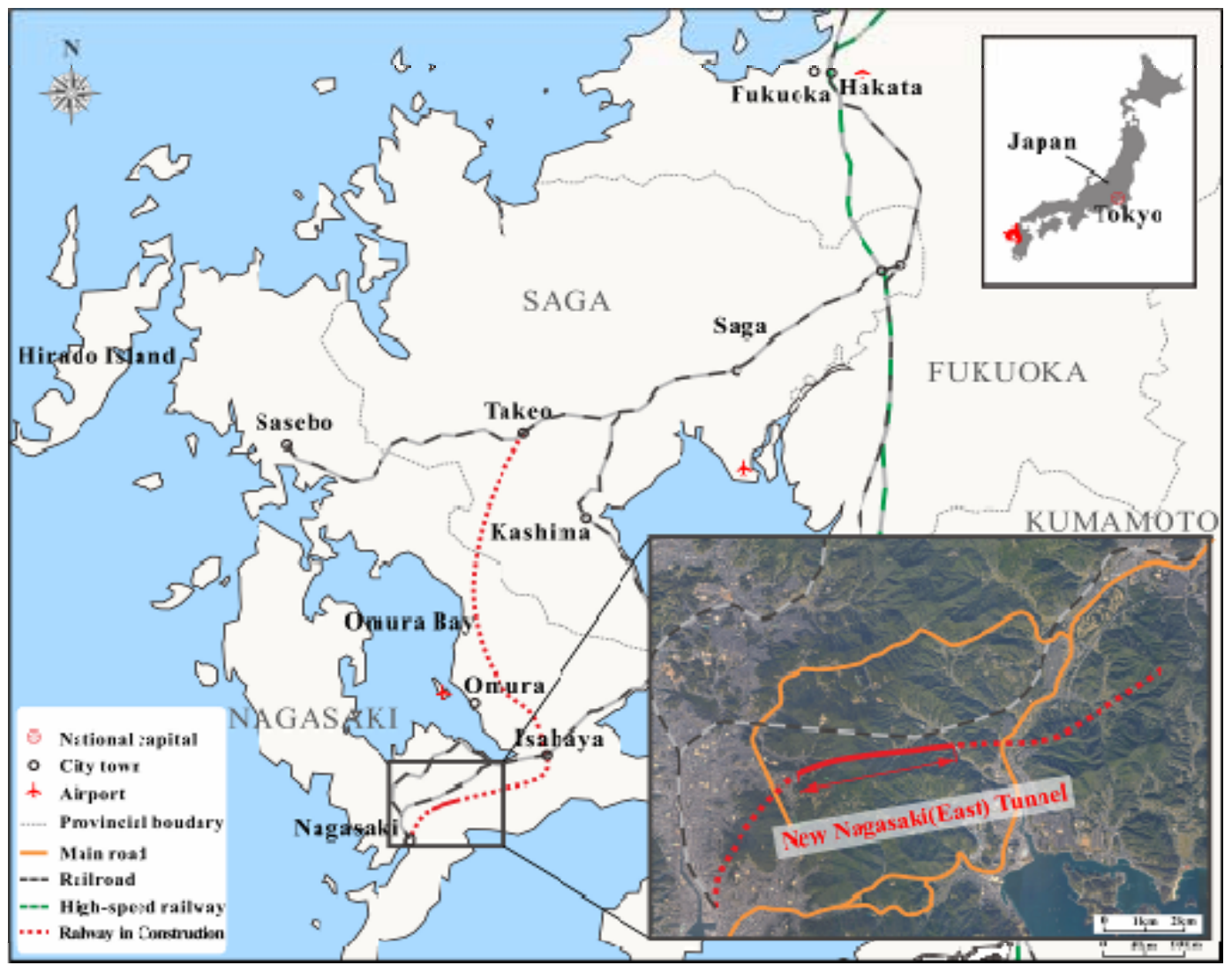

Fig.2 Location of new Nagasaki (east) tunnel, Nagasaki, Japan 


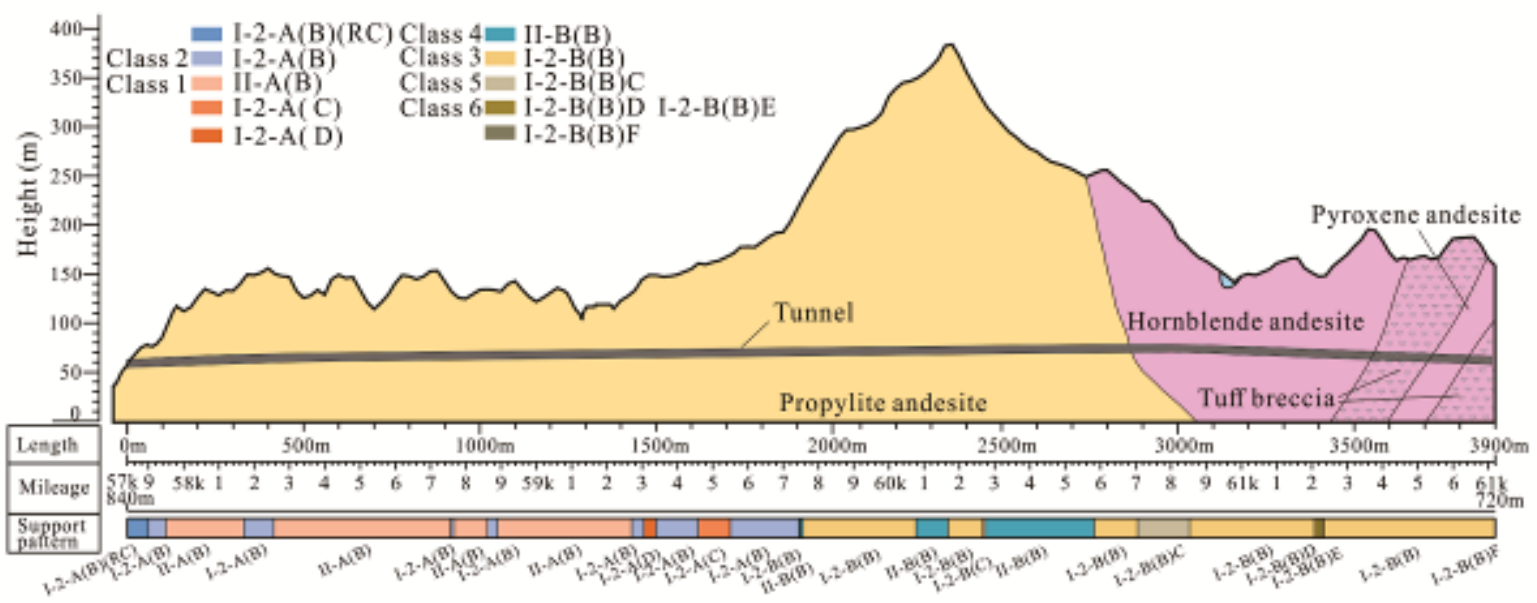

Fig.3 General view of the tunnel support patterns 


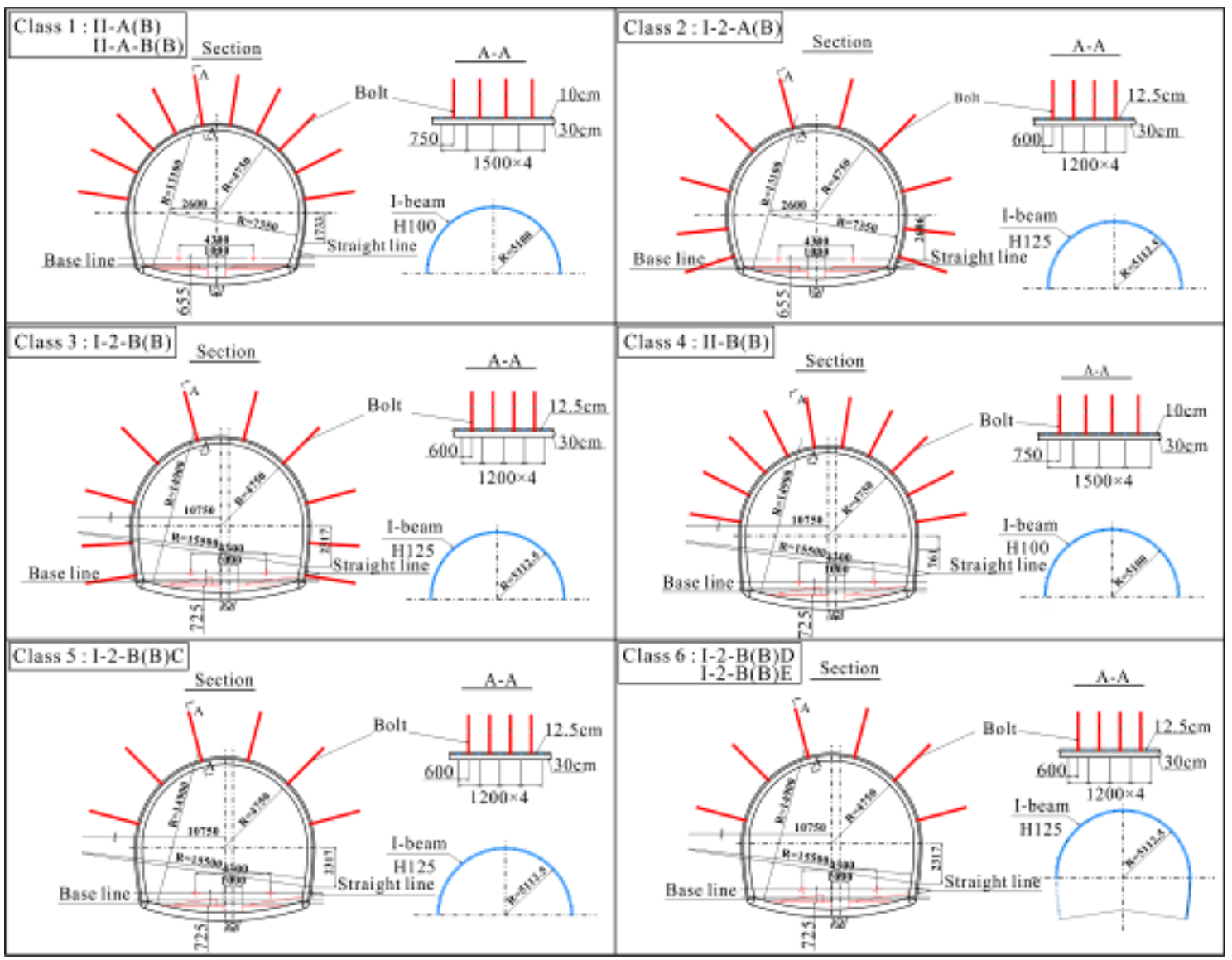

Fig.4 The details of the six support patterns 

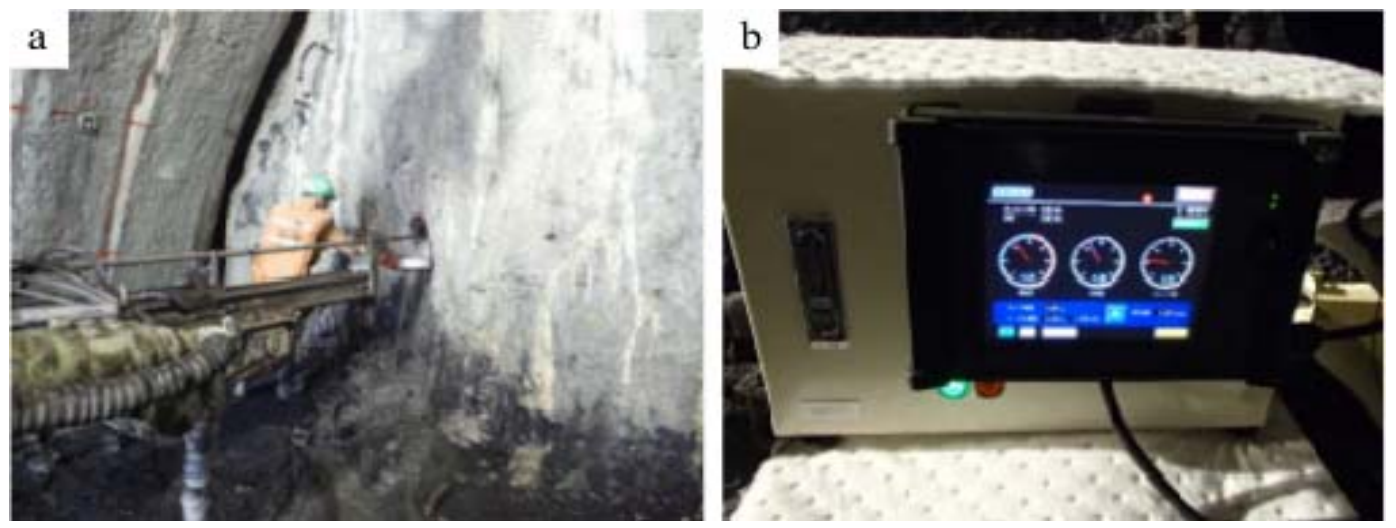

Fig.5 The drill and data collection device:(a) the hydraulic rotary percussion drill, (b) the measure while drilling (MWD) device

40 


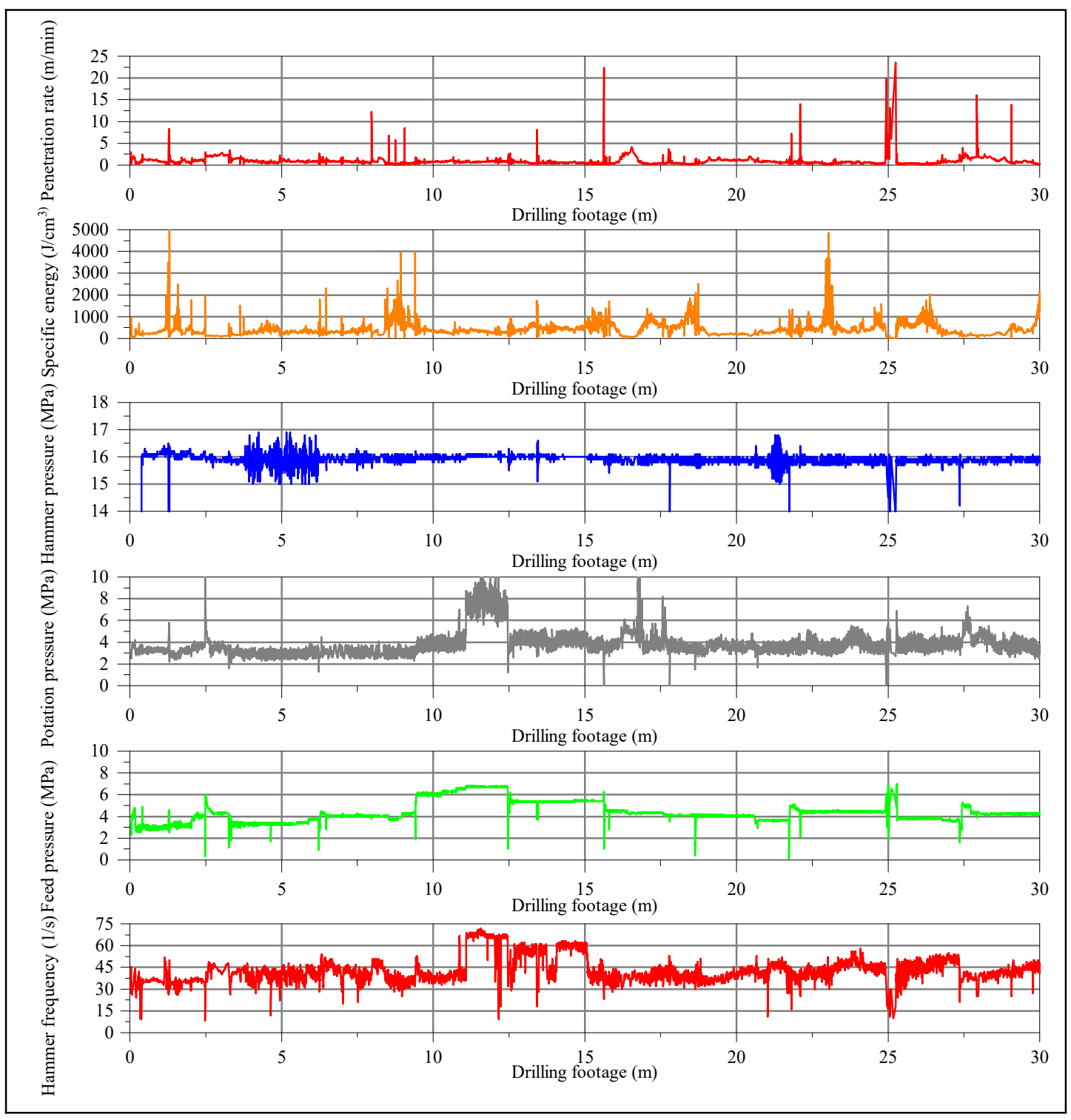

Fig.6 Visualization of the MWD data recorded 


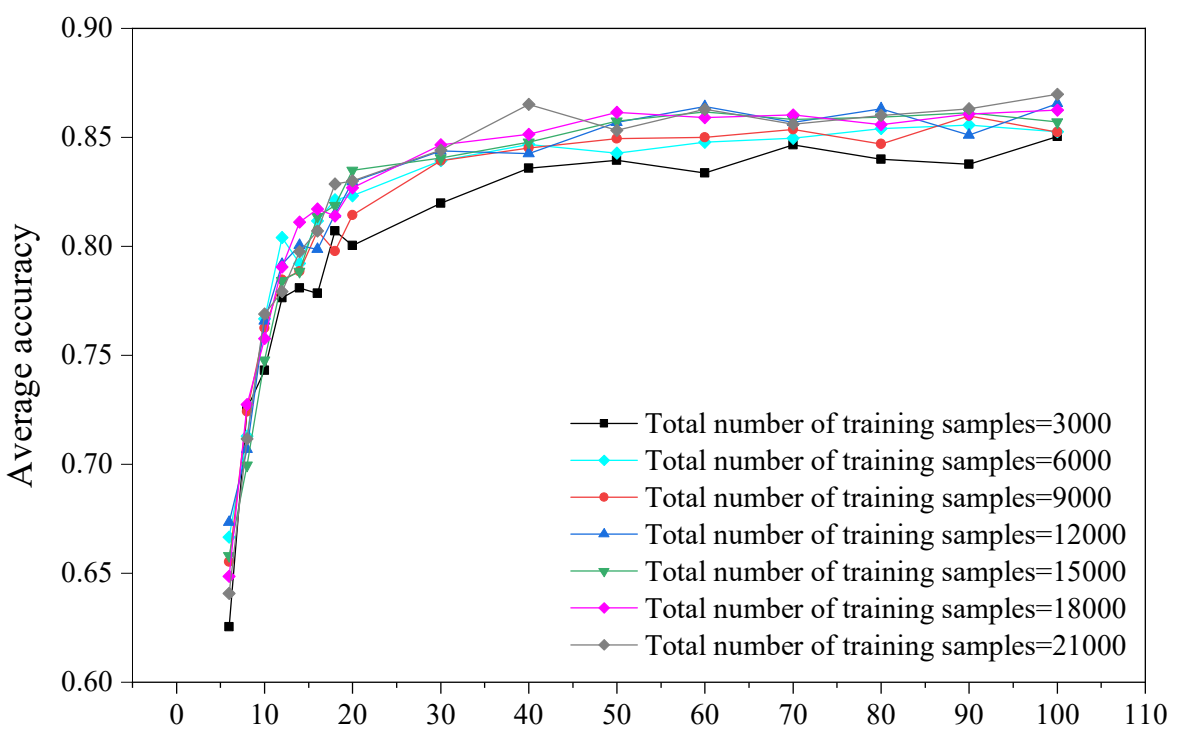

Number of hidden layer nodes

46 Fig. 7 Variations of the average accuracies with different number of training samples and nodes in 47 hidden layer 


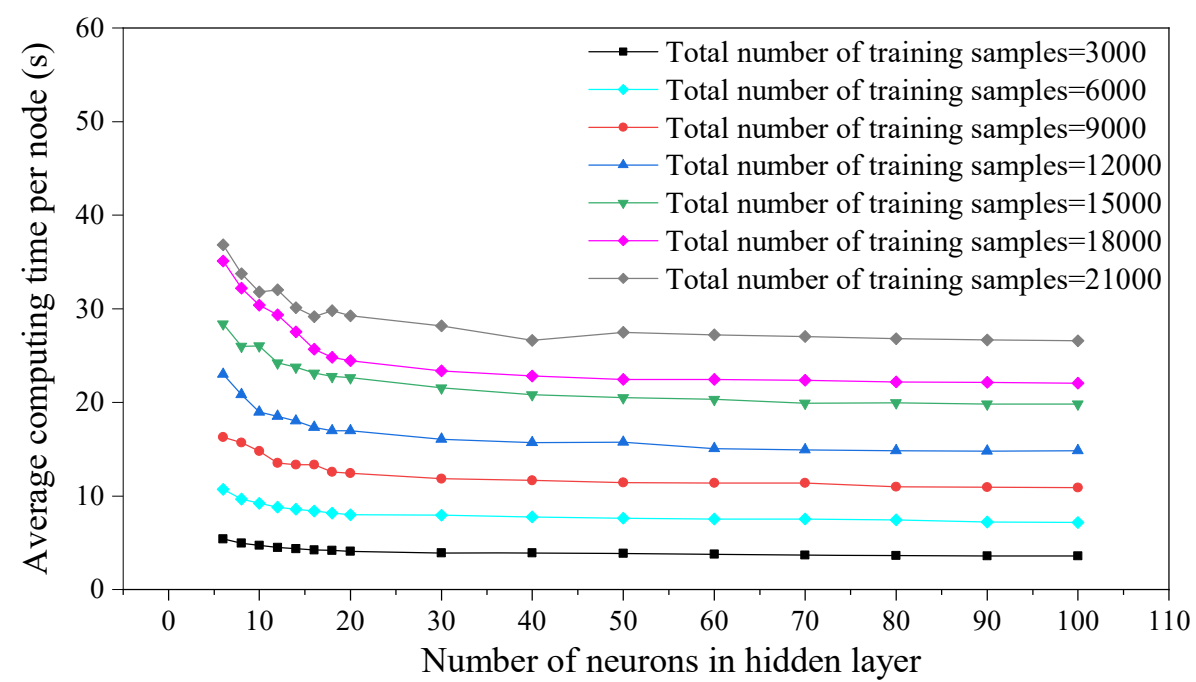

Fig. 8 Variations of the average computing time per node 


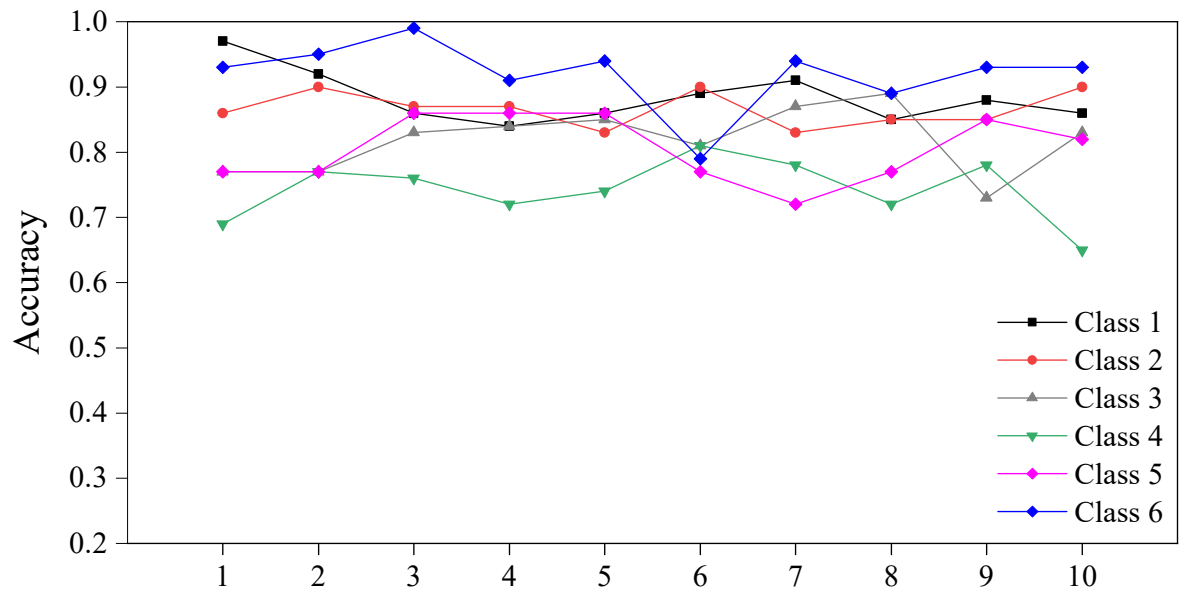

Times

Fig.9 Variations of the accuracies of estimation with each support pattern in 10 trials 


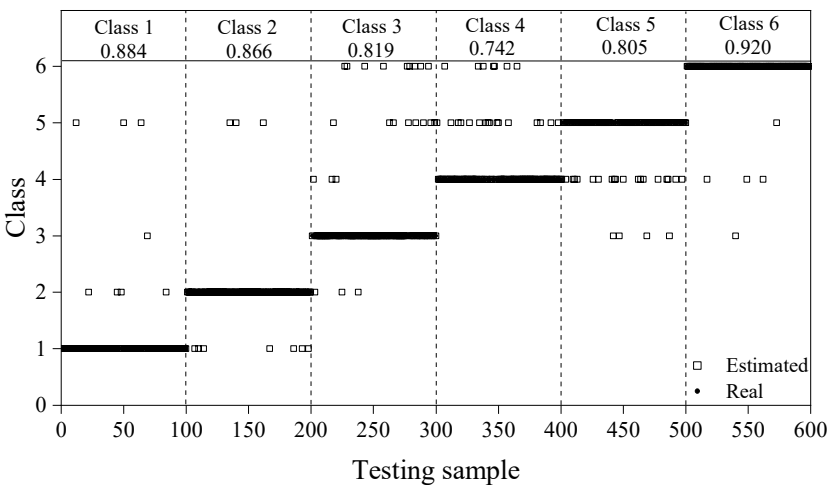

Fig. 10 Estimated results for the test sample 
Table 1 The classification number of support patterns

\begin{tabular}{|c|c|c|c|}
\hline Mileage & Distance $(\mathrm{m})$ & Support pattern & Class No. \\
\hline $57 \mathrm{~K} 840.0 \sim 57 \mathrm{~K} 900.0$ & 60.0 & $\mathrm{I}-2-\mathrm{A}(\mathrm{RC})(\mathrm{B})$ & - \\
\hline $57 \mathrm{~K} 900.0 \sim 57 \mathrm{~K} 948.0$ & 48.0 & $\mathrm{I}-2-\mathrm{A}(\mathrm{B})$ & - \\
\hline $57 \mathrm{~K} 948.0 \sim 58 \mathrm{~K} 150.0$ & 202.0 & II-A(B) & 1 \\
\hline $58 \mathrm{~K} 150.0 \sim 58 \mathrm{~K} 167.0$ & 17.0 & II-A-B (B) & 1 \\
\hline $58 \mathrm{~K} 167.0 \sim 58 \mathrm{~K} 259.4$ & 92.4 & $\mathrm{I}-2-\mathrm{A}(\mathrm{B})$ & 2 \\
\hline $58 \mathrm{~K} 259.4 \sim 58 \mathrm{~K} 750.9$ & 491.5 & II-A(B) & 1 \\
\hline $58 \mathrm{~K} 750.9 \sim 58 \mathrm{~K} 766.5$ & 15.6 & $\mathrm{I}-2-\mathrm{A}(\mathrm{B})$ & 2 \\
\hline $58 \mathrm{~K} 766.5 \sim 58 \mathrm{~K} 860.4$ & 93.9 & II-A(B) & 1 \\
\hline $58 \mathrm{~K} 860.4 \sim 58 \mathrm{~K} 890.4$ & 30.0 & $\mathrm{I}-2-\mathrm{A}(\mathrm{B})$ & 2 \\
\hline $58 \mathrm{~K} 890.4 \sim 59 \mathrm{~K} 269.9$ & 379.5 & $\mathrm{II}-\mathrm{A}(\mathrm{B})$ & 1 \\
\hline $59 \mathrm{~K} 269.9 \sim 59 \mathrm{~K} 303.5$ & 33.6 & $\mathrm{I}-2-\mathrm{A}(\mathrm{B})$ & 2 \\
\hline $59 \mathrm{~K} 303.5 \sim 59 \mathrm{~K} 339.5$ & 36.0 & $\mathrm{I}-2-\mathrm{A}(\mathrm{D})$ & - \\
\hline $59 \mathrm{~K} 339.5 \sim 59 \mathrm{~K} 460.1$ & 120.6 & $\mathrm{I}-2-\mathrm{A}(\mathrm{B})$ & 2 \\
\hline $59 \mathrm{~K} 460.1 \sim 59 \mathrm{~K} 555.1$ & 95.0 & $\mathrm{I}-2-\mathrm{A}(\mathrm{C})$ & - \\
\hline $59 \mathrm{~K} 555.1 \sim 59 \mathrm{~K} 746.1$ & 191.0 & $\mathrm{I}-2-\mathrm{A}(\mathrm{B})$ & 2 \\
\hline $59 \mathrm{~K} 746.1 \sim 59 \mathrm{~K} 747.1$ & 1.0 & $\mathrm{I}-2-\mathrm{B}(\mathrm{B})$ & 3 \\
\hline $59 \mathrm{~K} 747.1 \sim 59 \mathrm{~K} 756.1$ & 9.0 & II-B(B) & - \\
\hline $59 \mathrm{~K} 756.1 \sim 60 \mathrm{~K} 077.7$ & 321.6 & $\mathrm{I}-2-\mathrm{B}(\mathrm{B})$ & 3 \\
\hline $60 \mathrm{~K} 077.7 \sim 60 \mathrm{~K} 168.4$ & 90.7 & II-B(B) & 4 \\
\hline $60 \mathrm{~K} 168.4 \sim 60 \mathrm{~K} 269.2$ & 100.8 & $\mathrm{I}-2-\mathrm{B}(\mathrm{B})$ & 3 \\
\hline $60 \mathrm{~K} 269.2 \sim 60 \mathrm{~K} 275.2$ & 6.0 & $\mathrm{I}-2-\mathrm{B}(\mathrm{B}) \mathrm{C}$ & 5 \\
\hline $60 \mathrm{~K} 275.2 \sim 60 \mathrm{~K} 582.7$ & 307.5 & II-B(B) & 4 \\
\hline $60 \mathrm{~K} 582.7 \sim 60 \mathrm{~K} 705.1$ & 122.4 & $\mathrm{I}-2-\mathrm{B}(\mathrm{B})$ & 3 \\
\hline $60 \mathrm{~K} 705.1 \sim 60 \mathrm{~K} 856.3$ & 151.2 & $\mathrm{I}-2-\mathrm{B}(\mathrm{B}) \mathrm{C}$ & 5 \\
\hline $60 \mathrm{~K} 856.3 \sim 61 \mathrm{~K} 206.7$ & 350.4 & $\mathrm{I}-2-\mathrm{B}(\mathrm{B})$ & 3 \\
\hline $61 \mathrm{~K} 206.7 \sim 61 \mathrm{~K} 222.3$ & 15.6 & $\mathrm{I}-2-\mathrm{B}(\mathrm{B}) \mathrm{D}$ & 6 \\
\hline $61 \mathrm{~K} 222.3 \sim 61 \mathrm{~K} 234.3$ & 12.0 & $\mathrm{I}-2-\mathrm{B}(\mathrm{B}) \mathrm{E}$ & 6 \\
\hline $61 \mathrm{~K} 234.3 \sim 61 \mathrm{~K} 719.1$ & 484.8 & $\mathrm{I}-2-\mathrm{B}(\mathrm{B})$ & 3 \\
\hline $61 \mathrm{~K} 719.1 \sim 61 \mathrm{~K} 720.0$ & 0.9 & $\mathrm{I}-2-\mathrm{B}(\mathrm{B}) \mathrm{F}$ & - \\
\hline
\end{tabular}

61

Note: The mark "-" represents no drilling data

62 
Table 2 The comparison of details of the six support patterns

\begin{tabular}{|c|c|c|c|c|c|c|c|}
\hline Parameter & Uite & Class 1 & Class 2 & Class 3 & Class 4 & Class 5 & Class 6 \\
\hline Number of bolts & - & 10 & 10 & 10 & 10 & 6 & 6 \\
\hline Space of bolts & $\mathrm{mm}$ & 1500 & 1200 & 1200 & 1500 & 1200 & 1200 \\
\hline Type of I-beam & - & H100 & H125 & H125 & $\mathrm{H} 100$ & H125 & H125 \\
\hline Shape of I-beam & - & $\frown$ & $\frown$ & $\frown$ & $\frown$ & $\frown$ & ) \\
\hline Eccentric or not & logic & $\mathrm{N}$ & $\mathrm{N}$ & Y & $\mathrm{Y}$ & Y & $\mathrm{Y}$ \\
\hline Initial lining thickness & $\mathrm{cm}$ & 10 & 12.5 & 12.5 & 10 & 12.5 & 12.5 \\
\hline Secondary lining thickness & $\mathrm{cm}$ & 30 & 30 & 30 & 30 & 30 & 30 \\
\hline
\end{tabular}

64 
Table 3 Basic descriptive statistics for the original MWD data

\begin{tabular}{|c|c|c|c|c|c|c|c|c|c|c|}
\hline \multirow[b]{3}{*}{ Parameter } & \multirow[b]{3}{*}{ Symbol } & \multirow[b]{3}{*}{ Unit } & \multirow{3}{*}{$\begin{array}{c}\text { Class } \\
1 \\
\end{array}$} & \multirow{3}{*}{$\begin{array}{c}\begin{array}{c}\text { Support } \\
\text { pattern }\end{array} \\
\text { II-A(B) } \\
\text { Ave. }\end{array}$} & \multirow{2}{*}{\multicolumn{2}{|c|}{$\begin{array}{c}\begin{array}{c}\text { Number of } \\
\text { datasets }\end{array} \\
66514\end{array}$}} & \multirow{3}{*}{$\begin{array}{c}\text { Class } \\
2 \\
\end{array}$} & \multirow{3}{*}{$\begin{array}{c}\begin{array}{c}\text { Support } \\
\text { pattern }\end{array} \\
\text { I-2-A(B) } \\
\text { Ave. }\end{array}$} & \multicolumn{2}{|c|}{$\begin{array}{c}\text { Number of } \\
\text { datasets }\end{array}$} \\
\hline & & & & & & & & & \multicolumn{2}{|c|}{49228} \\
\hline & & & & & Min. & Max. & & & Min. & Max. \\
\hline Penetration rate & PR & $\mathrm{m} / \mathrm{min}$ & & 0.93 & 0.02 & 17.44 & & 0.89 & 0.00 & 22.16 \\
\hline Hammer pressure & HP & $\mathrm{MPa}$ & & 15.33 & 6.00 & 16.80 & & 14.15 & 5.10 & 19.30 \\
\hline Rotation pressure & $\mathrm{RP}$ & $\mathrm{MPa}$ & & 4.10 & 0.00 & 9.10 & & 3.65 & 0.00 & 18.20 \\
\hline Feed pressure & FP & $\mathrm{MPa}$ & & 4.64 & 0.10 & 7.70 & & 3.29 & 0.10 & 9.40 \\
\hline Hammer frequency & $\mathrm{HF}$ & $1 / \mathrm{s}$ & & 37.19 & 0.00 & 65.00 & & 30.43 & 0.00 & 62.00 \\
\hline \multirow[t]{3}{*}{ Specific energy } & $\mathrm{SE}$ & $\mathrm{J} / \mathrm{cm}^{3}$ & & 378.32 & 1.00 & 17028.00 & & 332.69 & 0.00 & 13062.80 \\
\hline & & & Class & $\begin{array}{c}\text { Support } \\
\text { pattern }\end{array}$ & \multicolumn{2}{|c|}{$\begin{array}{c}\text { Number of } \\
\text { datasets }\end{array}$} & Class & $\begin{array}{l}\text { Support } \\
\text { pattern }\end{array}$ & \multicolumn{2}{|c|}{$\begin{array}{l}\text { Number of } \\
\text { datasets }\end{array}$} \\
\hline & & & 3 & $\mathrm{I}-2-\mathrm{B}(\mathrm{B})$ & \multicolumn{2}{|c|}{75767} & 4 & II-B(B) & \multicolumn{2}{|c|}{81976} \\
\hline Parameter & Symbol & Unit & & Ave. & Min. & Max. & & Ave. & Min. & Max. \\
\hline Penetration rate & PR & $\mathrm{m} / \mathrm{min}$ & & 0.58 & 0.00 & 22.58 & & 0.45 & 0.02 & 4.99 \\
\hline Hammer pressure & HP & $\mathrm{MPa}$ & & 14.54 & 5.60 & 17.80 & & 14.77 & 5.20 & 16.80 \\
\hline Rotation pressure & $\mathrm{RP}$ & $\mathrm{MPa}$ & & 6.40 & 0.00 & 20.00 & & 5.15 & 0.00 & 12.50 \\
\hline Feed pressure & FP & $\mathrm{MPa}$ & & 4.39 & 0.20 & 9.10 & & 5.00 & 0.30 & 7.40 \\
\hline Hammer frequency & $\mathrm{HF}$ & $1 / \mathrm{s}$ & & 17.82 & 0.00 & 66.00 & & 26.66 & 0.00 & 57.00 \\
\hline \multirow[t]{3}{*}{ Specific energy } & SE & $\mathrm{J} / \mathrm{cm}^{3}$ & & 253.51 & 0.00 & 13598.00 & & 332.11 & 18.30 & 7013.40 \\
\hline & & & Class & $\begin{array}{l}\text { Support } \\
\text { pattern }\end{array}$ & \multicolumn{2}{|c|}{$\begin{array}{c}\text { Number of } \\
\text { datasets }\end{array}$} & Class & $\begin{array}{l}\text { Support } \\
\text { pattern }\end{array}$ & \multicolumn{2}{|c|}{$\begin{array}{l}\text { Number of } \\
\text { datasets }\end{array}$} \\
\hline & & & 5 & $\mathrm{I}-2-\mathrm{B}(\mathrm{B}) \mathrm{C}$ & \multicolumn{2}{|c|}{35413} & 6 & $\mathrm{I}-2-\mathrm{B}(\mathrm{B}) \mathrm{D}$ & \multicolumn{2}{|c|}{9751} \\
\hline Parameter & Symbol & Unit & & Ave. & Min. & Max. & & Ave. & Min. & Max. \\
\hline Penetration rate & PR & $\mathrm{m} / \mathrm{min}$ & & 0.49 & 0.00 & 3.01 & & 0.76 & 0.06 & 4.99 \\
\hline Hammer pressure & HP & $\mathrm{MPa}$ & & 14.92 & 6.10 & 16.00 & & 14.33 & 12.50 & 16.00 \\
\hline Rotation pressure & $\mathrm{RP}$ & $\mathrm{MPa}$ & & 5.03 & 2.50 & 9.90 & & 7.65 & 3.50 & 15.10 \\
\hline Feed pressure & FP & $\mathrm{MPa}$ & & 3.98 & 0.50 & 6.40 & & 3.83 & 0.70 & 6.10 \\
\hline Hammer frequency & $\mathrm{HF}$ & $1 / \mathrm{s}$ & & 26.84 & 0.00 & 55.00 & & 20.10 & 0.00 & 56.00 \\
\hline Specific energy & SE & $\mathrm{J} / \mathrm{cm}^{3}$ & & 269.11 & 0.00 & 7210.80 & & 182.98 & 16.90 & 2389.50 \\
\hline
\end{tabular}


67 Table 4 The proposed number of nodes in hidden layer. ( $N_{i}$ : number of input nodes, $N_{0}$ : number of output 68 nodes)

\begin{tabular}{lll}
\hline Formula & This study $\left(N_{i}=6, N_{0}=6\right)$ & Reference \\
\hline$\leqslant 2 \times N_{i}+1$ & $\leqslant 13$ & Hecht-Nielsen, 1987 \\
$3 N_{i}$ & 18 & Hush, 1989 \\
$\left(N_{i}+N_{0}\right) / 2$ & 6 & Ripley, 1993 \\
$\frac{2+N_{o} \times N_{i}+0.5 N_{o} \times\left(N_{o}^{2}+N_{i}\right)-3}{N_{i}+N_{o}}$ & 13 & Paola, 1994 \\
$\sqrt{N_{i}\left(N_{0}+2\right)}+1$ & 8 & Gao, 1998 \\
$\sqrt{N_{i} \times N_{o}}$ & 6 & Masters, 1993; Kaastra and Boyd, 1996 \\
$2 N_{i}$ & 12 & Kanellopoulos and Wilkinson, 1997 \\
\hline
\end{tabular}

69 
70 Table 5 The average accuracy rates of prediction of support pattern selections (with the number of nodes 71 in hidden layer $=30$, the number of training samples $=6000$ ).

\begin{tabular}{ccccccc}
\hline Parameter & Class 1 & Class 2 & Class 3 & Class 4 & Class 5 & Class 6 \\
\hline Predicted $\bar{A}$ & 0.884 & 0.866 & 0.819 & 0.742 & 0.805 & 0.920 \\
\hline
\end{tabular}

72 